\title{
IL-27 Counteracts Neuropathic Pain Development Through Induction of IL-10
}

\section{OPEN ACCESS}

Edited by:

Felipe Almeida Pinho Ribeiro, Harvard Medical School,

United States

Reviewed by:

Felipe J. Nobre Lelis,

Brigham and Women's Hospital and

Harvard Medical School,

United States

Rafael Gonzalez-Cano,

Boston Children's Hospital and

Harvard Medical School, United States

Larissa Staurengo-Ferrari, University of California, San Francisco, United States

*Correspondence:

Thiago M. Cunha

thicunha@fmrp.usp.br

${ }^{\dagger}$ Present address:

Miriam M. Fonseca,

Pain Mechanisms Laboratory, Department of Anesthesiology, Wake

Forest School of Medicine,

Winston-Salem, NC, United States

Specialty section:

This article was submitted to

Multiple Sclerosis and

Neuroimmunology,

a section of the journal

Frontiers in Immunology

Received: 16 October 2019

Accepted: 16 December 2019

Published: 28 January 2020

Citation:

Fonseca MM, Davoli-Ferreira M

Santa-Cecília F, Guimarães RM, Oliveira FFB, Kusuda R, Ferreira DW,

Alves-Filho JC, Cunha FQ and

Cunha TM (2020) IL-27 Counteracts

Neuropathic Pain Development

Through Induction of IL-10.

Front. Immunol. 10:3059.

doi: 10.3389/fimmu.2019.03059

\author{
Miriam M. Fonseca ${ }^{1 \dagger}$, Marcela Davoli-Ferreira ${ }^{1,2}$, Flávia Santa-Cecília ${ }^{1}$, \\ Rafaela M. Guimarães ${ }^{1,2}$, Francisco F. B. Oliveira ${ }^{1}$, Ricardo Kusuda ${ }^{1}$, David W. Ferreira ${ }^{1}$, \\ José C. Alves-Filho ${ }^{1}$, Fernando Q. Cunha ${ }^{1}$ and Thiago M. Cunha ${ }^{1 *}$ \\ ${ }^{1}$ Department of Pharmacology, Center for Research in Inflammatory Diseases (CRID), Ribeirão Preto Medical School, \\ University of São Paulo (USP), Ribeirão Preto, Brazil, ${ }^{2}$ Graduate Program in Basic and Applied Immunology, Ribeirão Preto \\ Medical School, University of São Paulo (USP), Ribeirão Preto, Brazil
}

Neuroimmune-glia interactions have been implicated in the development of neuropathic pain. Interleukin-27 (IL-27) is a cytokine that presents regulatory activity in inflammatory conditions of the central nervous system. Thus, we hypothesized that IL-27 would participate in the neuropathic pain process. Here, we found that neuropathic pain caused by peripheral nerve injury (spared nerve injury model; SNI), was enhanced in IL-27-deficient ${ }^{(-/-)}$mice, whereas nociceptive pain is similar to that of wild-type mice. SNI induced an increase in the expression of IL-27 and its receptor subunit (Ws $\times 1)$ in the sensory ganglia and spinal cord. IL-27 receptor was expressed mainly in resident macrophage, microglia, and astrocytes of the sensory ganglia and spinal cord, respectively. Finally, we identify that the antinociceptive effect of IL-27 was not observed in IL-10-/- mice. These results provided evidence that IL-27 is a cytokine produced after peripheral nerve injury that counteracts neuropathic pain development through induction of the antinociceptive cytokine IL-10. In summary, our study unraveled the role of IL-27 as a regulatory cytokine that counteracts the development of neuropathic pain after peripheral nerve damage. In conclusion, they indicate that immunotherapies based on IL-27 could emerge as possible therapeutic approaches for the prevention of neuropathic pain development after peripheral nerve injury.

Keywords: neuropathic pain, cytokines, IL-27, IL-10, glial cells, macrophages

\section{INTRODUCTION}

Chronic neuropathic pain is caused by diseases or lesions affecting the somatosensory nervous system. Often resistant to different types of therapies, neuropathic pain affects $\sim 3-17 \%$ of the chronic pain population in the world (1). Many studies have shown that neuroimmune response in nociceptive pathway has an important role for the development of neuropathic pain (2-4). Different forms of injury to the peripheral nervous systems, evoked by traumatic, metabolic, or toxic events, can lead to abnormal neuronal response from the site of damage to the sensory ganglia and then the central nervous system (CNS), inducing an intense neuroinflammation response in these sites $(5,6)$. Non-neuronal cells, including satellite glial cells, macrophages, microglia, and astrocytes, along the nociceptive pathway can be activated, which influence the neuronal excitability and consequently participate in the establishment of chronic pain states (7-9). In the local of 
nerve injury, sensory ganglia, and spinal cord, non-neuronal cells can release a diverse range of proinflammatory mediators, which may directly or indirectly amplify pain signaling $(10,11)$. On the other hand, in order to control the inflammatory and nociceptive responses, these cells can also release anti-inflammatory mediators, such as IL-4, IL-10, IL-13, and transforming growth factor beta (TGF- $\beta$ ) and pro-resolving mediators such as resolvins, lipoxins, protectins, and maresins, which regulate the response to nerve damage and might attenuate pain behavior in animal models of chronic pain (12-16). Another cytokine that appears to control the inflammatory response in the periphery and CNS is interleukin-27 (IL-27) (17).

IL-27 is a member of the IL-6/IL-12 heterodimeric cytokine family, formed by two subunits, Epstein-Barr virus-induced gene 3 (EBI3) and p28. It binds to a receptor composed of gp130 (shared with other cytokine receptors, including IL6R) and IL-27R $\alpha$ (also known as WSX-1 or TCCR), which is specific for IL-27 $(18,19)$. IL-27 is generally produced by antigen-presenting cells, such as macrophages and dendritic cells; however, some studies suggest that it can be released by astrocytes and microglia in CNS $(20,21)$, and the signaling for IL-27 subunit production is induced by immune stimuli and different pathogens $(18,22)$. IL-27 is remarkably characterized by immunosuppressive and anti-inflammatory functions mediated by the production of IL-10 and suppression of IL-17 expression $(20,23,24)$. IL-27 can suppress the differentiation of naïve $T$ cells toward IL-17-producing $\mathrm{T}$ cells (Th17). It also promotes differentiation of activated $\mathrm{T}$ cells to $\mathrm{T}$ cells able to secrete IL10 in an antigen-specific manner, named type 1 regulatory $(\operatorname{Tr} 1)$ T cells $(25,26)$.

The immunomodulatory activity of IL-27 has been demonstrated in several in vivo models. WSX-1-deficient mice develop an excessive inflammatory response during infections and in autoimmune disease models $(27,28)$. In a model of infection in the CNS induced by the JHM strain of mouse hepatitis virus, IL-27 promotes the production of IL-10, which is essential for controlling inflammation response (29). In addition, in a murine model of experimental encephalomyelitis (EAE), treatment with recombinant IL-27 delays the onset of EAE and improves the clinical signs of the disease (30). Furthermore, IL-27 has demonstrated potential therapeutic action in the rheumatoid arthritis model (31-33). Although many studies are showing the importance of IL-27 in neuroimmune-mediated diseases, there is no study investigating its role in the pathophysiology of neuropathic pain. Herein,

\footnotetext{
Abbreviations: CNS, central nervous system; CX3CR1, motif chemokine receptor 1; DRG, dorsal root ganglion; EAE, experimental autoimmune encephalomyelitis; EBI3, epstein-barr virus-induced 3; ELISA, enzyme-linked immunosorbent assay; GFAP, glial fibrillary acidic protein; i.p, intraperitoneal injection; i.t, intrathecally injection; IBA-1 (Aif1), ionized calcium-binding adapter molecule 1; IL-4, interleukin 4; IL-10, interleukin 10; IL-13, interleukin 13; IL-17, interleukin 17; IL-18, interleukin 18; IL-1 $\beta$, interleukin 1 beta; IL-27, interleukin 27; IL-27r, recombinant mouse IL-27 protein; mg, milligram; PBS, phosphate-buffered saline; PFA, paraformaldehyde; pg, picogram; Sham, false-operated animals; SNI, spared nerve injury; TGF- $\beta$, transforming growth factor beta; Th17, T helper 17 cell; $\mathrm{TNF} \alpha$, tumor necrosis factor alpha; Tr1, type 1 regulatory cells; WT, wild type.
}

we showed that IL-27 is upregulated in the dorsal root ganglia (DRGs) and spinal cord of mice after peripheral nerve injury (spared nerve injury, SNI). Moreover, we showed that IL-27 counteracted the development of neuropathic pain through the induction of IL-10 production.

\section{METHODS}

\section{Animals}

The experiments were performed in C57BL/6 wild-type (WT) male mice (6-8 weeks old) and C57BL/6 mice deficient $\left(^{-/-}\right)$ in the following proteins: IL-27 (EBI3) (34) and IL-10 (35), as well as in transgenic animals expressing the green fluorescent protein (GFP) in cells that express CX3C chemokine receptor $1\left(\mathrm{CX} 3 \mathrm{CR} 1^{\mathrm{GFP} /+}\right)(36)$. Local colonies of transgenic mice were then established and maintained on a C57BL/6 background at the animal care facility of Ribeirão Preto Medical School, University of São Paulo. The controls and transgenic mice were not littermates. The animals were taken to the testing room at least $1 \mathrm{~h}$ before the experiments. Food and water were available ad libitum. All behavioral tests were performed between 8:00 a.m. and 5:00 p.m.

\section{Drugs and Chemicals}

The following drugs were obtained from the sources indicated: recombinant mouse IL-27 (NS0-expressed) protein (IL-27r) (2799-ML-010, R\&D, Minneapolis, USA) and diazepam (D0899, Sigma, St Louis, MO, USA). Acetone (Fisher Chemical, Gell, Belgium). Formalin solution (1\%) was prepared using $37 \%$ formaldehyde (Fisher Chemical Gell, Belgium) in 0.9\% sodium chloride saline solution (Baxter hospitalar, São Paulo, Brazil). To prepare $1 \mathrm{~L}$ of phosphate-buffered saline (PBS), $0.1 \mathrm{M}$ was used with $9 \mathrm{~g}$ of $\mathrm{NaCl}, 0.122 \mathrm{~g}$ of $\mathrm{KH}_{2} \mathrm{PO}_{4}$, and $0.814 \mathrm{~g}$ of $\mathrm{Na}_{2} \mathrm{HPO}_{4}$ (Sigma-Aldrich, St. Louis, NO, USA) in distilled water $(\mathrm{pH}=7.4)$.

\section{Neuropathic Pain Model}

A model of persistent peripheral neuropathic pain, the spared nerve injury (SNI), was induced as previously described (37). Briefly, under isoflurane anesthesia, the sciatic nerve and their three terminal branches (the sural, common peroneal, and tibial nerves) were exposed at lower-thigh level by blunt dissection through the biceps femoris muscle. The common peroneal and tibial nerves were tightly ligated with 6.0 silk, while the sural nerve was spared. The nerves distal to the ligature were sectioned. The experimental control group consisted of falseoperated animals (Sham). In these animals, there was exposure of the sciatic nerve similarly to the SNI group, but without any manipulation of nerves. Muscle and skin were closed in layers. Then, mechanical pain hypersensitivity and cold allodynia were evaluated on specific days.

\section{Behavioral Nociceptive Tests}

An investigator blinded to group allocation performed all the behavior tests. 


\section{Formalin Assay}

We assessed formalin-evoked nociception by injection of $20 \mu \mathrm{l}$ of formalin (1\%) into the dorsal surface of the right hind paw of two groups of male mice: IL-27 $7^{-/}$and WT-naive mice. The time in seconds spent licking or flinching the injected paw was recorded and expressed as the total time of nociceptive behaviors in the early phase (0-10 $\mathrm{min})$ and late phase (10-50 $\mathrm{min}$ ) after formalin injection (38).

\section{Hot Plate Test}

The noxious thermal thresholds of the hind paws were examined in $\mathrm{IL}-27^{-/-}$and WT-naive mice via hot plate test using an electrically heated surface (Ugo Basile, model 35100, Gemonio VA, Italy) at different temperatures $\left(48,50,52\right.$, and $\left.56^{\circ} \mathrm{C}\right)$. For each specified temperature, each animal was placed on the heated plate, and time responses to the thermal stimulus (jumping, withdrawal, and licking of the hind or front paws) were recorded in seconds. The cutoff time used was $20 \mathrm{~s}$ to avoid possible injury in the animal paws (39).

\section{Acetone Test}

In different days after SNI, IL-27 ${ }^{-/-}$, and WT mice were placed in a clear plastic box with a wire mesh floor and allowed to habituate for $30 \mathrm{~min}$ prior to testing. Then, $50 \mu \mathrm{l}$ fluid (acetone) was sprayed on the plantar surface of the right hind paw using a syringe of $1 \mathrm{ml}$ (Tuberculin slip tip, BD, Franklin Lake, NJ, USA). Paw withdrawal response, defined as flinching, licking, or biting of the limb, was measured within 1 min after the application of acetone (40). The acetone test was measured after the paw mechanical withdrawal threshold test was done.

\section{Mechanical Nociception Test}

The mechanical nociceptive threshold was evaluated in WT, IL$27^{-/-}$, and IL- $10^{-/-}$mice that were placed on an elevated wire grid, and the plantar surface of the ipsilateral hind paw was stimulated perpendicularly with a series of von Frey filaments (Stoelting, Chicago, IL, USA), with logarithmically increasing stiffness (0.008-2.0 g) (41). The withdrawal frequency was calculated as a percentage of withdrawals after 10 applications of $0.008 \mathrm{~g}$ von Frey filament in the right hind paw.

\section{Rota-rod Test}

To discard possible non-specific muscle relaxant or sedative effects of recombinant mouse IL-27, mice motor performance was evaluated on the rota-rod test (42). The apparatus consisted of a bar with a diameter of $2.5 \mathrm{~cm}$, subdivided into six compartments by disks $25 \mathrm{~cm}$ in diameter (Ugo Basile, Model $7600)$. The bar rotated at a constant speed of 22 rotations per minute. WT-naive animals were selected $24 \mathrm{~h}$ previously by eliminating those mice that did not remain on the bar for two consecutive periods of $120 \mathrm{~s}$. Then, those animals were treated intrathecally with vehicle (saline) or recombinant IL27 (100 ng) in a final volume of $5 \mu \mathrm{l}$ using a BD UltraFine ${ }^{\circledR}(29 G)$ insulin syringe (BD, Franklin Lakes, NJ, USA). Diazepam (5 mg/kg, intraperitoneal) was used as a positive control. To inject diazepam solution, $1 \mathrm{ml}$ sub-Q syringe and needle $26 \mathrm{G}$ x 5/8 (BD, Franklin Lakes, NJ, USA) were used. The cutoff time used was $120 \mathrm{~s}$.

\section{Intrathecal Injection}

Under isoflurane (2\%) anesthesia, recombinant IL-27 (100 ng) or vehicle (saline) was administered intrathecally (i.t.) in WT and IL-10 $-/-$ mice. The technique used for intrathecal injection was described by Papir-Kricheli et al. (43), modified by holding the mice securely in one hand by the pelvic girdle and inserting a $\mathrm{BD}$ Ultra-Fine ${ }^{\circledR}(29 G)$ insulin syringe (BD, Franklin Lakes, NJ, USA) directly on the subarachnoid space (close to L4-L5 segments) of the spinal cord. A sudden lateral movement of the tail indicated proper placement of the needle in the intrathecal space. For all administrations, 5- $\mu$ l volume was used. Then, the syringe was held in the specific position for a few seconds and progressively removed to avoid any outflow of the drug.

\section{Quantitative Real-Time PCR}

At the indicated times after nerve injury, mice were anesthetized and then perfused with $0.1 \mathrm{M}$ PBS. DRGs and spinal cord, ipsilateral to the lesion, were collected from the region correspondent to lumbar segments (L3-L5) and homogenized in TRI Reagent ${ }^{\circledR}$ (Life Technologies Corporation, Carlsbad, CA, USA) reagent at $4^{\circ} \mathrm{C}$. Then, total cellular mRNA was purified from whole tissues, according to the manufacturer's instructions. After FACS sorting procedure, $\sim 25,000$ cells were used to isolate mRNA using RNeasy micro kit ${ }^{\circledR}$ (Qiagen, Hiden, Germany). To convert the mRNA in cDNA, high-capacity cDNA Reverse Transcription Kit (Thermo Fisher Scientific, Graiciuno, Vilnius, LT) was used. The level of each gene was normalized to the levels of the mouse Gapdh gene, and the results were analyzed by the method of quantitative relative expression $2^{-\Delta \Delta C T}$ as previously described (44). Primer pairs for mouse Gapdh, Aif1, Gfap, Tnf, $I l 1 b, E b i 3, p 28, W s x 1, I l 12 p 35$, and Il10 were as follows:

Gapdh fwd: 5'-CATCTTCTTGTGCAGTGCCA- $3^{\prime}$

Gapdh rev: 5'-CGGCCAAATCCGTTCAC-3'

Aif1 fwd: 5' -TGAGGAGCCATGAGCCAAAG-3'

Aif1 rev: 5'-GCTTCAAGTTTGGACGGCAG-3'

Gfap fwd: 5' -AGGGCGAAGAAAACCGCATCACC-3'

Gfap rev: 5' -TCTAAGGGAGAGCTGGCAGGGCT-3'

Tnf fwd: $5^{\prime}$-TGTGCTCAGAGCTTTCAACAA- $3^{\prime}$

Tnf rev: $5^{\prime}$-CTTGATGGTGGTGCATGAGA-3'

$I l 1 b$ fwd: $5^{\prime}$-TGACAGTGATGATGAGAATGACCTGTTC-3'

Illb rev: 5' -TTGGAAGCAGCCCTTCATCT-3'

Il27 (Ebi3) fwd: 5' -TGCCATGCTTCTCGGTATCC-3'

Il27 (Ebi3) rev: 5'-AGGGTCCGGCTTGATGATTC-3'

Il27 (p28) fwd: 5'-GGCTATGTCCACAGCTTTGCT-3'

Il27 (p28) rev: 5' -CGAAGTGTGGTAGCGAGGAA-3'

Wsx1: Taqman ${ }^{\circledR}:$ Mm00497259_m1

Il12p35 fwd: 5'-AAGACATCACACGGGACCAAA-3'

Il12p35 rev: 5'-CAGGCAACTCTCGTTCTTGTGTA-3'

Illo fwd: 5' -AACAAAGGACCAGCTGGACAAC-3'

Illo rev: 5'-GCAACCCAAGTAACCCTTAAAGTC-3'

\section{Immunofluorescence}

At day 10 after surgery, WT and $\mathrm{CX} 3 \mathrm{CR} 1^{\mathrm{GFP} /+}$ mice were deeply anesthetized with ketamine and xylazine and perfused 
transcardially with phosphate buffer $0.1 \mathrm{M}$, followed by fresh $4 \%$ paraformaldehyde (PFA) in PBS $0.1 \mathrm{M}$ ( $\mathrm{pH} 7.4)$. After the perfusion, segments of spinal cord lumbar correspondent L3, L4, and L5 were dissected out, post-fixed for $2 \mathrm{~h}$ in PFA, and then replaced with $30 \%$ sucrose overnight. Transverse spinal sections (free-floating, $60 \mu \mathrm{m}$ ) were cut in a cryostat. The floating sections were used for immunofluorescence assays as previously described (45). Then, the sections were incubated overnight at $4{ }^{\circ} \mathrm{C}$ with polyclonal primary antibodies: anti-WSX1 (1:250) (5996-Abcam), anti-GFAP (1:500) conjugated with alexa fluor 488 (MAB 3042X-Millipore), anti-NeuN (1:250) (MAB377-Millipore), and anti-GFP (1:500) conjugated with FITC (ab6662-Abcam), for the tissue from CX3CR1 ${ }^{\mathrm{GFP} /+}$ mice. After washing, the sections were then incubated with the appropriate secondary antibody solution for $2 \mathrm{~h}$ at room temperature; all secondary solutions were diluted 1:500: Alexa fluor 594, Alexa fluor 488, or Alexa fluor 647 (Invitrogen). The sections were washed with PBS as described earlier, mounted on glass slides, and covered with coverslips with Fluromount ${ }^{\mathrm{TM}}$ Aqueous Mounting Medium (Sigma). The sections of spinal cord were acquired using a SP5 confocal laser scanning microscope (Leica, Wetzlar, Germany). Colocalization was ensured with confocal $\mathrm{Z}$ stacks at $1-\mu \mathrm{m}$ intervals and visualization in threedimensional orthogonal planes.

\section{Cell Sorting}

Cell sorting of $\mathrm{CD}_{11 \mathrm{~b}}{ }^{+}$and $\mathrm{CD} 45^{-}$cells from DGRs was performed as described previously (46). Briefly, the ipsilateral DRGs (L3, L4, and L5 pooled from eight animals) were collected at day 10 from WT or IL-27 ${ }^{-/}$mice submitted to SNI or Sham surgery, as well as from WT mice submitted to SNI and treated for five consecutive days (starting on day 10 up to day 14) with recombinant IL-27 (100 $\mathrm{ng} /$ in a final volume of $5 \mu \mathrm{l}$ ) or vehicle (i.t). DRGs were incubated in $5 \mathrm{ml}$ of RPMI medium containing $2 \mathrm{mg} / \mathrm{ml}$ of collagenase type II (Sigma Aldrich) for $1 \mathrm{~h}$ at $37^{\circ} \mathrm{C}$. After this time, the tissues were passed through a cell strainer $(40 \mu \mathrm{m})$, followed by centrifugation with RPMI medium containing 10\% fetal bovine serum (FBS, Gibco). Cells obtained were resuspended in $0.1 \mathrm{M}$ PBS containing $10 \%$ of rabbit serum, to avoid non-specific background staining, and specific monoclonal antibodies for $30 \mathrm{~min}$ at $4^{\circ} \mathrm{C}$. The following monoclonal antibodies (BD Biosciences) were used for staining: CD45-BV421 (clone 30-F11), Ly6G-FITC (clone 1A8), and CD11b-APCCy7 (clone M1/70); the antibodies were diluted 1:250. Cells were isolated using FACSAria III (BD Biosciences), and then the pellets obtained were resuspended in lysis buffer to isolate mRNA. For all of the experiments, sample purity was $\sim 70 \%$ for CD11b+ Ly6G- cells and $\sim 90 \%$ for CD $45-$ cells. The data were analyzed using FlowJo 10 software (Treestar, Ashland, USA). The gating strategy used to perform cell sorting from sensory ganglia is depicted in Figure $\mathbf{S} \mathbf{1}$.

\section{Cytokine Measurement by ELISA}

At 7 and 10 days after nerve injury, mice were anesthetized and then perfused with $0.1 \mathrm{M}$ PBS. The ipsilateral DRGs and lumbar segments of the spinal cord (L3, L4, and L5 pooled from two animals) from WT or IL-27 $-/-$ mice were collected and homogenized in lysis buffer containing protease inhibitors (to each $10 \mathrm{mg}$ of tissue, $100 \mu \mathrm{l}$ of lysis buffer was used); the supernatant without dilution was used to measure IL-10. Mouse DuoSet ELISA kit to IL-10 was purchased from R\&D Systems and performed as instructed by the manufacturer. The results are expressed as picogram (pg) of cytokines per milligram (mg) of tissue protein. The protein concentration of the lysate was determined using a Pierce ${ }^{\mathrm{TM}}$ bicinchoninic acid assay protein assay kit (Thermo Scientific, Rockford, IL, USA).

\section{Data Analyses and Statistics}

Data are reported as means \pm SEM. The normality of the distribution of data was analyzed by D'Agostino and Pearson tests. Two-way ANOVA followed by Bonferroni's $t$-test was used to compare the groups and doses at different times (curves) when the responses (nociception) were measured. The factors analyzed were treatment, time, and time vs. treatment interaction. Alternatively, if the responses (nociception, protein expression, mRNA expression) were measured only once after stimulus injection, the differences between responses were evaluated by one-way ANOVA followed by Bonferroni's $t$-test (for three or more groups), comparing all pairs of columns. For comparisons of groups across two groups, an unpaired Student $t$-test was used. $P<0.05$ were considered significant. Statistical analysis was performed with GraphPad Prism (GraphPad Software, San Diego, CA, USA).

\section{RESULTS}

\section{IL-27 Counteracts the Development of Neuropathic Pain but Is Not Involved in Basal Control of Nociception Threshold}

We first characterized the physiological nociceptive response of IL-27 $7^{-/}$mice. WT and IL-27 ${ }^{-/-}$mice were assessed behaviorally after acute peripheral application of different stimuli. IL-27 ${ }^{-/}$mice exhibited the same intensity of mechanical pain threshold (using von Frey filament) and thermal pain threshold (temperatures of $48,50,52$, and $56^{\circ} \mathrm{C}$ ) compared to WT mice (Figures 1A-C). Furthermore, IL$27^{-1-}$ mice also showed no difference in nociceptive behaviors in the early and late phase of the formalin test compared to WT mice (Figure 1D). These data indicate that, under normal physiological conditions, IL-27 is not involved in acute nociception. Next, we determined whether IL-27 plays a role in the development of chronic neuropathic pain induced by SNI. The injured WT mice (WT-SNI) showed an increase in mechanical hypersensitivity (more percentage of frequency response), starting on day 3 and reaching the maximal response at day 10 , which persists until day 21 compared to sham-operated WT mice (WT-Sham). In contrast, IL-27 ${ }^{-/-}$mice submitted to SNI (IL-27-/- - SNI) displayed a significant increase in mechanical hypersensitivity after nerve injury on day 5 until day 10 compared to WT-SNI mice (Figure 1E). Similarly, WT-SNI mice showed an increase in cold hypersensitivity, starting on day 3 until day 21, compared to Sham-WT mice. Furthermore, IL-27-/- SNI animals also showed increased levels of cold 
hypersensitivity when compared to WT-SNI mice (Figure 1F). Taken together, these data indicate that IL-27 signaling might be negatively controlling the development of neuropathic pain but is not involved in the detection of mechanical, thermal, and chemical nociception in basal conditions.

\section{Peripheral Nerve Injury Triggers an Increase in the Expression of IL-27 and Its Receptor-Specific Subunit, WSX-1, in Spinal Cord and Dorsal Root Ganglia}

To explore the role of IL-27 signaling in the development of neuropathic pain, we evaluated the levels of mRNA expression of IL-27 subunits ( $p 28$ and Ebi3) and Wsx1, a specific subunit of its receptor, in ipsilateral lumbar DRGs (L3-L5) and spinal cord of WT animals after SNI induction. We detected that p28 expression was upregulated between days 7 and 14 in the DRGs and spinal cord of WT-SNI mice compared to WT-Sham mice (Figures 2A,E). Ebi3 expression increased either in DRGs and spinal cord after SNI at all times evaluated (Figures 2B,F). Wsx1 expression was also upregulated in the DRGs (10 days after SNI) and at day 7 in the spinal cord of WT-SNI mice compared to WT-Sham mice (Figures 2C,G). To exclude the participation of IL-35 cytokine because it is formed by EBI3 and IL12p35, we analyzed the gene expression of Il12p35 in the same tissues; however, we did not detect any difference in all times analyzed (Figures 2D,H). Altogether these results indicate that after peripheral nerve injury, IL-27 and its specific receptor subunit, but not IL-35, are upregulated in the sensory ganglia and spinal cord.

\section{WSX-1 Is Expressed in Microglia and Astrocytes in the Spinal Cord and in the Macrophages of DRGs After Peripheral Nerve Injury}

Next, we sought to analyze which cell type might be expressing the IL-27 receptor in the sensory ganglia and spinal cord after peripheral nerve injury. In naïve animals, the immunoreactivity for WXS-1 is very low in the dorsal horn of the spinal cord (Figure 3A), corroborating the mRNA data; however, WSX-1 expression is upregulated in the spinal cord at 10 days after SNI. WSX-1 is expressed in the spinal cord cells that also express CX3CR1 and GFAP, but not NeuN (Figure 3B). Thus, these data suggest that after peripheral nerve injury, WXS-1 expression might be upregulated in microglia and astrocytes, but not in neurons of the spinal cord.

In an attempt to evaluate in which cell type WSX-1 might be expressed in sensory ganglia, at day 10 after SNI or Sham surgeries, DRGs were harvested and $\mathrm{CD} 45^{-}$and $\mathrm{CD} 11 \mathrm{~b}^{+} \mathrm{Ly}_{6 \mathrm{G}}{ }^{-}$ cells (macrophages) were purified using FACS sorting. Then, we analyzed Wsx1 gene expression in these cells. It was found that Ws 1 mRNA was only detected in $\mathrm{CD}_{11} \mathrm{~b}^{+} \mathrm{Ly}_{6 \mathrm{G}}^{-}$cells, and the expression was upregulated after SNI in these cells compared to cells from Sham-operated mice (Figure 3C). These results suggest that, in the sensory ganglia, Wsx 1 is mainly expressed in macrophages, and peripheral nerve injury induces an increase in its expression.

\section{The Impact of IL-27 Deficiency in the Activation of Immune/Glial Cells and Cytokine Production in the DRGs and Spinal Cord After Peripheral Nerve Injury}

Peripheral nerve injury induces the activation of resident macrophages in the sensory ganglia and glial cells (microglia and astrocytes) in spinal cord that account for the development of neuropathic pain through the production of pro-inflammatory cytokines such as TNF and IL-1 $\beta(2,4,47,48)$. Since the expression of IL-27 receptor is mainly observed in glial/immune cells of the spinal cord and DRGs after peripheral nerve injury, we hypothesize that the role of IL-27 in counteracting neuropathic pain might be through regulating these neuroimmune-glia processes. Thus, we analyzed the gene expression of Aif1 (IBA-1) and Gfap as indicators of the macrophages/microglial cell and satellite glial/astrocyte activation in the DRGs and spinal cord, respectively. In all times and tissues evaluated, the expression of Aif1 and Gfap in IL-27-/- - SNI mice was not different from WT-SNI mice (Figures 4A,E,B,F). Furthermore, the expression of Tnf and $I l 1 b$ was also not different between IL-27-/- - SNI and WT-SNI mice (Figures 4C,D,G,H).

There is evidence that the immunoregulatory role of IL-27 is dependent on its ability to induce IL-10 production $(23,28,29)$. Furthermore, IL-10 is a well-known anti-nociceptive cytokine that reduces the development of pathological pain, including neuropathic pain (49-51). Based on these evidences, we analyzed next the interference of IL-27 deficiency on IL-10 production in DRGs and spinal cord after peripheral nerve injury. Notably, it was found that the expression of IL-10 (mRNA and protein) in the DRGs and spinal cord was reduced in IL-27-/- - SNI mice when compared to WT-SNI mice (Figures 5A-D). Collectively, these results indicate that IL-27 is a triggering mechanism of IL-10 production after peripheral nerve injury; however, it has minimum effect on immune/glial cell activation and pronociceptive cytokine production.

\section{Exogenous IL-27 Reduced Neuropathic Pain Through the Induction of IL-10}

Since IL-27 ${ }^{-/}$animals presented higher signs of neuropathic pain, it might indicate that exogenous IL-27 would be a useful tool to reduce neuropathic pain. In this context, we analyzed whether the intrathecal administration of recombinant IL-27 could affect the mechanical pain hypersensitivity induced by SNI. Previously, we conducted a long series of experiments in an attempt to find the best dose and time for recombinant IL-27 treatments (data not shown). We found that on day 10 after SNI induction, the treatment of animals intrathecally with recombinant IL-27 (100 ng/site), twice a day, was able to reduce mechanical pain hypersensitivity (Figure 6A). It is noteworthy that this dose of recombinant IL-27 neither changed the mechanical withdrawal threshold of naive mice nor caused motor impairment, discarding possible non-specific muscle relaxant or sedative effects of recombinant IL-27 (Figures 6B,C).

Next, we sought to evaluate whether the antinociceptive effect of exogenous IL-27 on neuropathic pain would be dependent on IL-10. For this, WT and IL- $10^{-/-}$mice were submitted 

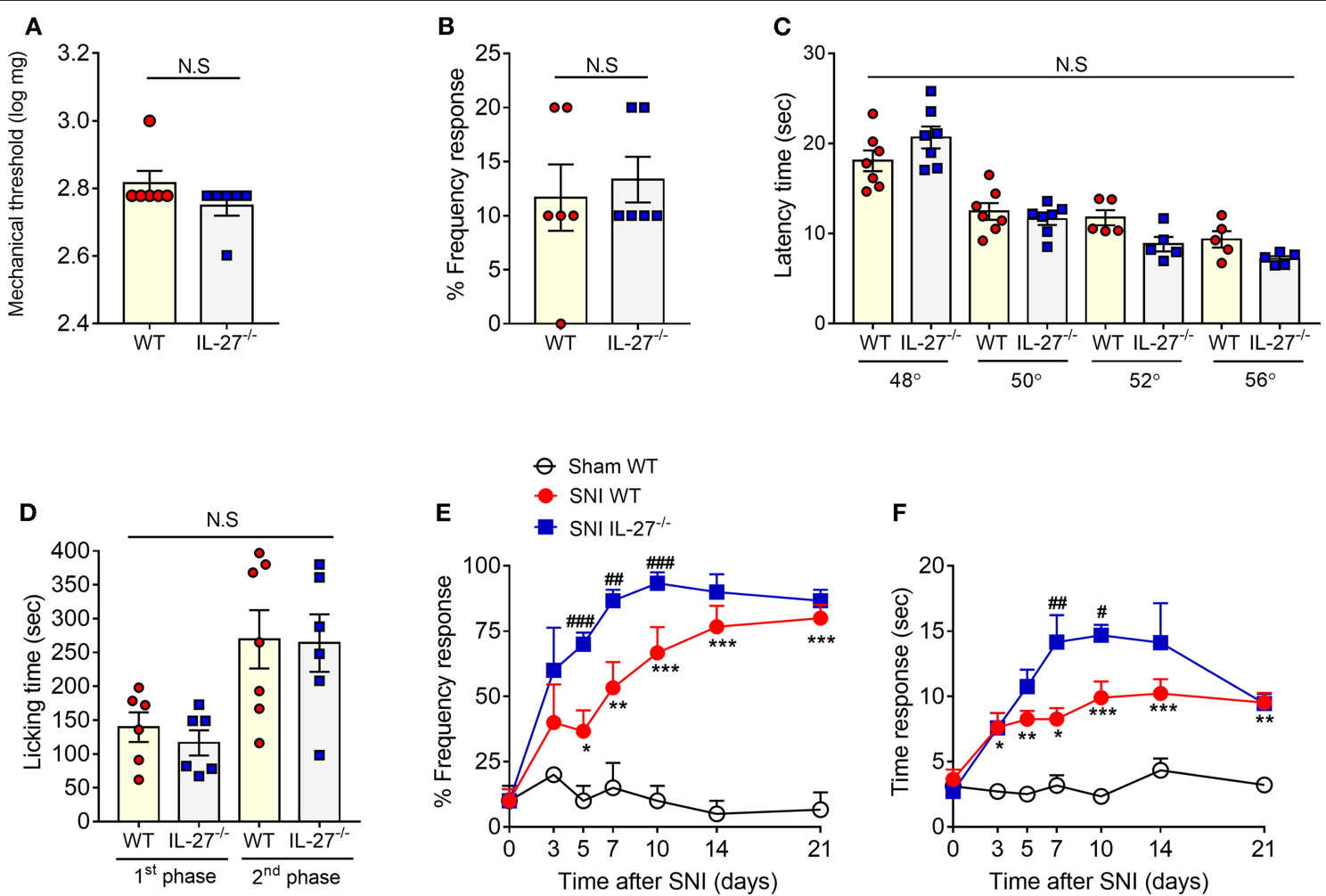

FIGURE 1 | IL-27 signaling is not involved in nociceptive pain but protects the animals in neuropathic pain condition. Different behavior tests were realized in WT and IL-27-1- mice: mechanical nociceptive threshold using von Frey filaments $(\mathbf{A})(n=6)$. Percentage of withdrawal frequency using von Frey filaments (B) $(n=6)$. Thermal nociceptive threshold using hot plate test at different temperatures (C) $(n=6)$. Total duration (seconds) of nociceptive behavior for $0-10$ min (first phase) and for 10 up to 50 min (second phase) after administration of formalin in the paw (D) $(n=6)$. Mechanical nociception test using percentage of withdrawal frequency (E) $(n=8)$ and acetone test $(\mathbf{F})(n=8)$, in which values represent withdrawal threshold before (day 0$)$ and up to 21 days after nerve injury (SNI) or in sham-operated mice. Data are presented as means \pm S.E.M. ${ }^{\star} P<0.05$, ${ }^{\star \star} P<0.01,{ }^{\star \star \star} P<0.001$ vs. Sham-WT and $\# P<0.05$, $\# \# P<0.01$, \#\#\#P<0.001 vs. SNI-WT. Data were analyzed by $t$-test (A-D) and two-way ANOVA followed by Bonferroni post-test (E,F).

to peripheral nerve injury (SNI), and at day 10 after surgery we detected mechanical hypersensitivity development in these animals. Different groups of mice were treated with daily doses of recombinant IL-27 (100 ng/site) or vehicle up to day 14 (Figure 7A). As already shown, the treatment with recombinant IL-27 reduced the mechanical pain hypersensitivity in WTSNI. However, this antinociceptive effect of IL-27 has not been observed in IL-10 $10^{-/-}$SNI mice (Figure 7B). Corroborating these data, the treatment of WT-SNI mice with recombinant IL27 promoted an upregulation of $I l 10$ expression in the DRGs and spinal cord when compared to mice submitted to SNI treated with vehicle (Figures 7C,D). Supporting our previous finding that IL-27 receptor is mainly expressed in $\mathrm{CD}_{11 \mathrm{~b}}{ }^{+}$ cells in the DRGs (Figure 3C), we found that the upregulatory effect of recombinant IL-27 treatment on IL-10 expression is only observed in $\mathrm{CD} 1 \mathrm{~b}^{+}$cells compared to non-immune cells (CD45- cells) (Figure 7E). Lastly, we sought to confirm that IL10 cytokine expression after peripheral nerve injury depends on IL-27 action in myeloid cells in the DRGs. WT and IL-27-/mice were submitted to SNI or Sham surgeries. At day 10 after injury, DRGs were collected, and $\mathrm{CD}^{-} 5^{-}$(non-immune cells) and $\mathrm{CD}_{11 \mathrm{~b}^{+}}$cells (macrophages) were isolated by FACS sorting.
Then, we analyzed the gene expression of Il10 in these types of cells. It was found that only $\mathrm{CD}_{11} \mathrm{~b}^{+}$cells from WT animals submitted to SNI expressed $I l 10$, which was reduced in $\mathrm{CD}_{11 \mathrm{~b}^{+}}$ cells from IL-27-/- SNI animals (Figure 7F). Altogether these results indicate that the antinociceptive effect of exogenous and endogenous IL-27 upon neuropathic pain caused by peripheral nerve injury depends on the induction of IL-10 expression on myeloid cells in the DRGs.

\section{DISCUSSION}

Neuropathic pain is a challenging condition often refractory to different therapies. It is well-known that neuroimmune-glia interactions play a crucial role in the development of neuropathic pain. In this context, understanding the function of each cytokine in neuropathic pain pathophysiology might provide potential opportunities to amplify the arsenal of treatment options available (52). The main signaling molecules of the immune system are cytokines, which can be largely categorized as either pro- or anti-inflammatory. Elevated pro-inflammatory cytokine signal has been associated with symptoms of pain after nerve injury, whereas cytokines such as IL-10 and IL-4 are 


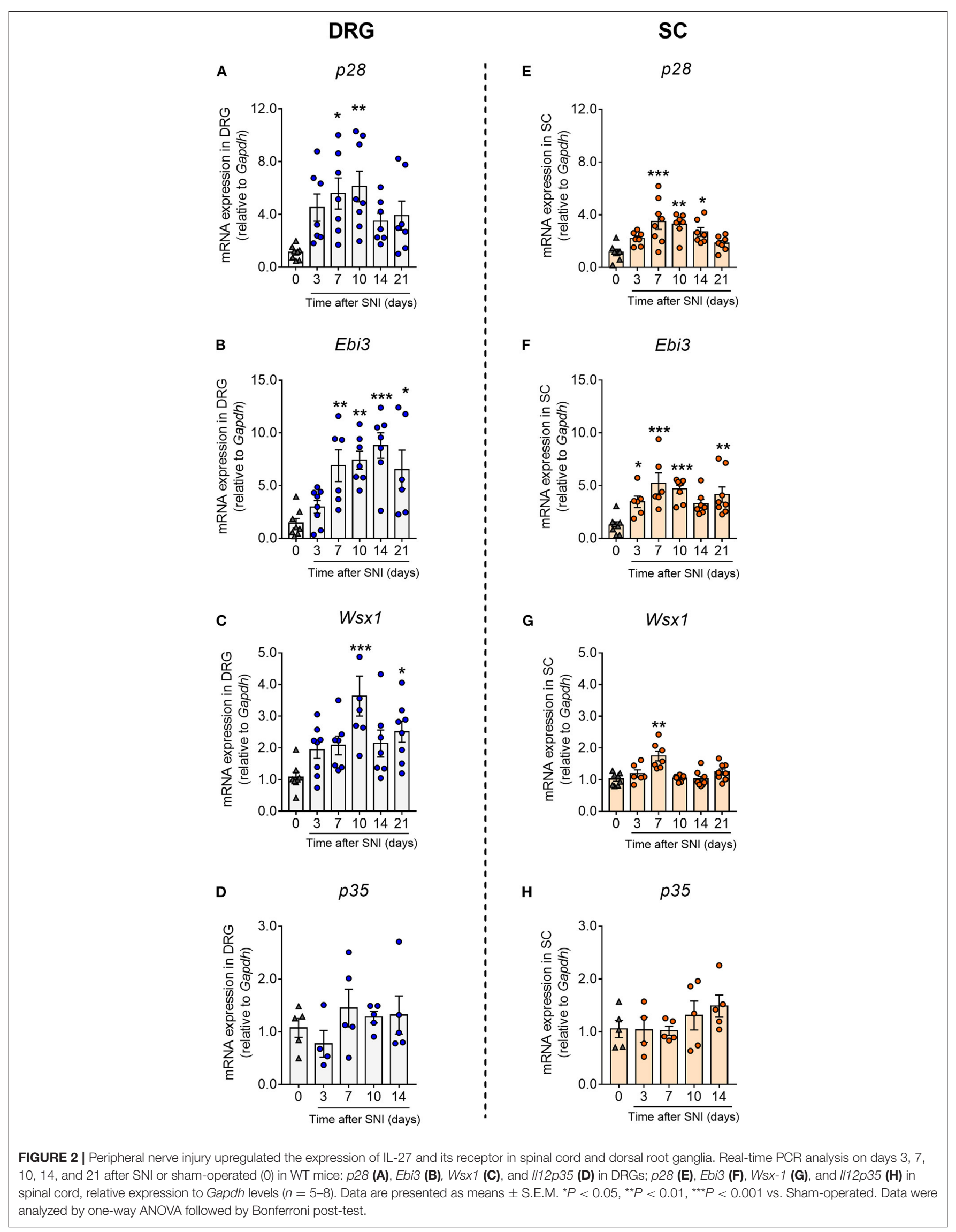



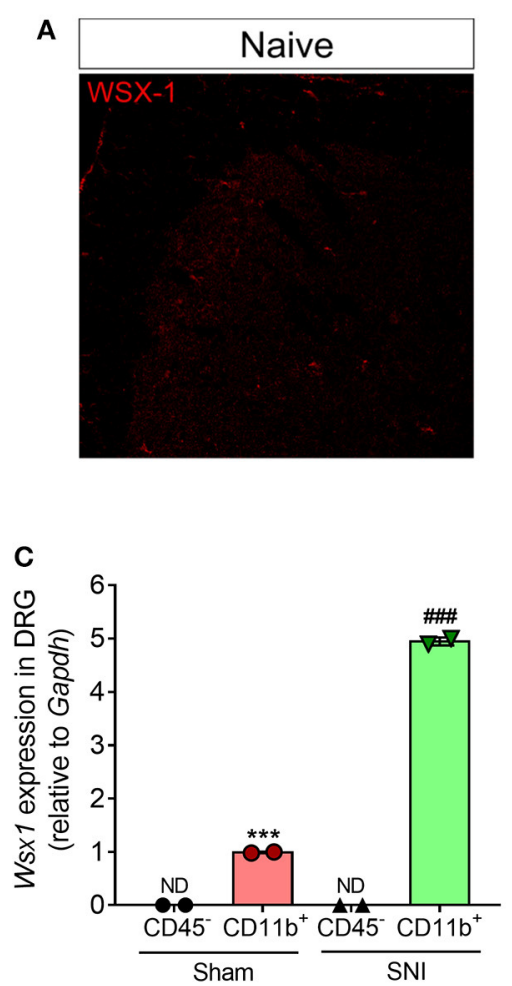

B

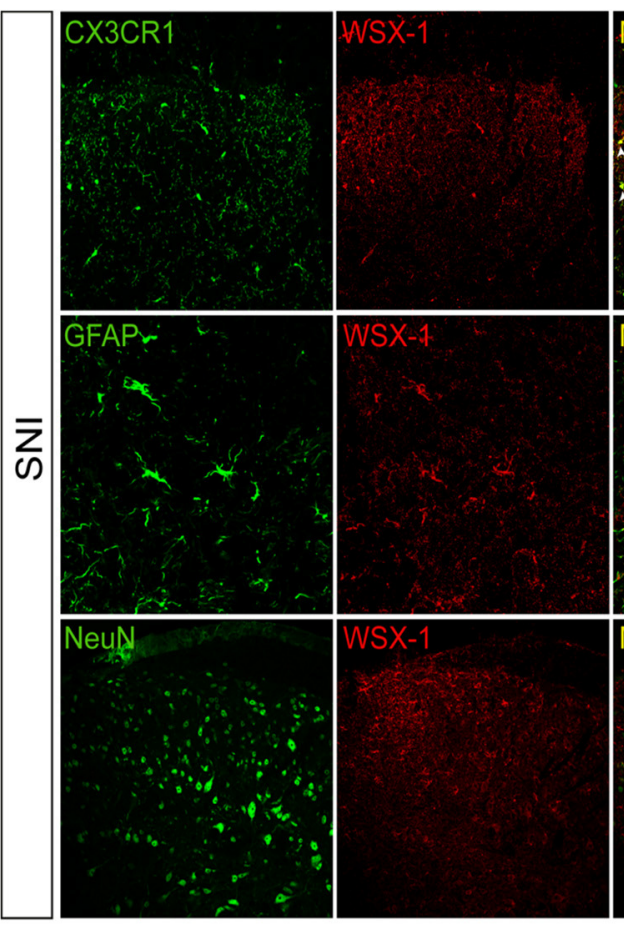

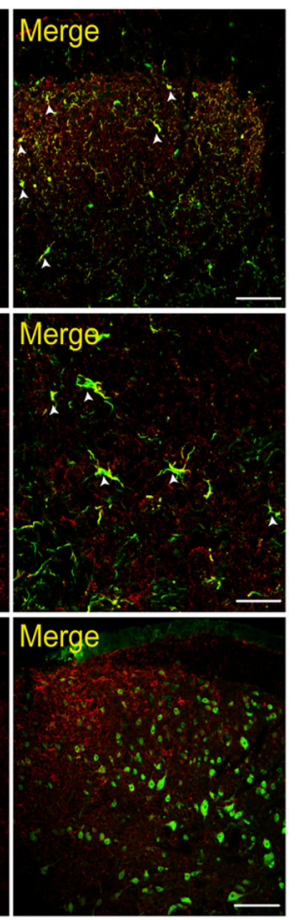

FIGURE 3 | Peripheral nerve injury induces WSX-1 expression in glial cells in spinal cord and in macrophage of DRGs. Representative confocal images of spinal cord at day 10 after SNI in CX3CR1 GFP/+ and WT mice. (A) Spinal cord from CX3CR1 GFP/+_naive mice labeled with WSX-1 (red). (B) Sections from CX3CR1 GFP/+ and WT mice were double-labeled marked with WSX-1 (magenta or red; middle panels), GFAP (green; left and middle panels), or NeuN (green; left panel, above). The merged images are shown in the right panels (yellow indicates double-positive cells, followed by arrows). Scale bars, 25 uM ( $n=4$ ). (C) Real-time PCR analysis of Ws 1 expression relative to Gapdh levels in CD45- and CD11b+ cells isolated, by FACS sorting, from DRGs of SNI or Sham-operated WT mice at day 10 after surgery ( $n=2$, pool from eight animals for each). Data are presented as means \pm S.E.M. ${ }^{\star \star \star} P<0.001$ vs. CD45- from Sham. \#\#\#P<0.001 vs. CD11b+ from Sham. ND, not detected. Data were analyzed by one-way ANOVA followed by Tukey post-test.

associated with the downregulation of the immune system and neuropathic pain relief $(47,52-54)$. Here, we provided evidence that IL-27 counteracts neuropathic pain development through the induction of anti-inflammatory cytokine IL-10.

Our findings demonstrate that IL-27 protects animals against the development of mechanical and cold pain hypersensitivity after peripheral nerve injury, two major symptoms of neuropathic pain. On the other hand, our data indicate that IL-27 did not participate in the nociceptive pain caused by different stimuli modalities, which was different from a previous report showing that the deficiency of IL-27 and its signaling constitutively control thermal and mechanical nociceptive thresholds (19). Although the explanation for these differences is not immediately apparent, it could be due to the difference in the source of the mutant mice. Nevertheless, our data show that the expression of IL-27 receptor is very low in the nociceptive pathway at naïve condition, favoring the idea that IL-27 would have little or no participation in nociceptive pain. Despite this controversy, it was shown that IL-27-deficient mice present higher mechanical sensitivity when submitted to inflammatory and neuropathic pain models compared to WT animals (19), supporting our data. Furthermore, the data showing that peripheral nerve injury induced upregulation of IL-27 subunits (EBI3 and p28) and its receptor subunit (WSX-1) in important structures of the nociceptive pathway (DRGs and spinal cord) argue in favor of the regulatory role of IL-27 in the development of neuropathic pain.

The neuroimmune-glia interactions across the pain pathway play a crucial role in the development of neuropathic pain (4). For instance, peripheral nerve injury triggers the activation/proliferation of macrophages in the DRGs and glial cells (microglia and astrocytes) in the spinal cord (4). These glial cells mediate the development of neuropathic pain through the production of several neuroactive molecules (55-58). It is noteworthy that IL-27 receptor-specific subunit WXS-1 (17) is expressed in different leukocyte populations such as macrophages $(18,59,60)$, microglia, and astrocytes from the brain of multiple sclerosis patients (21). Our results extend these findings, indicating that after peripheral nerve injury, WSX-1 expression in the DRGs and spinal cord was mainly observed in immune or glial cells. Based on those findings and on the fact that IL-27 is an important immunoregulatory cytokine $(24,28)$, we analyzed whether IL-27 counteracts neuropathic pain development through the modulation of macrophage/glial 


\section{DRG}

A
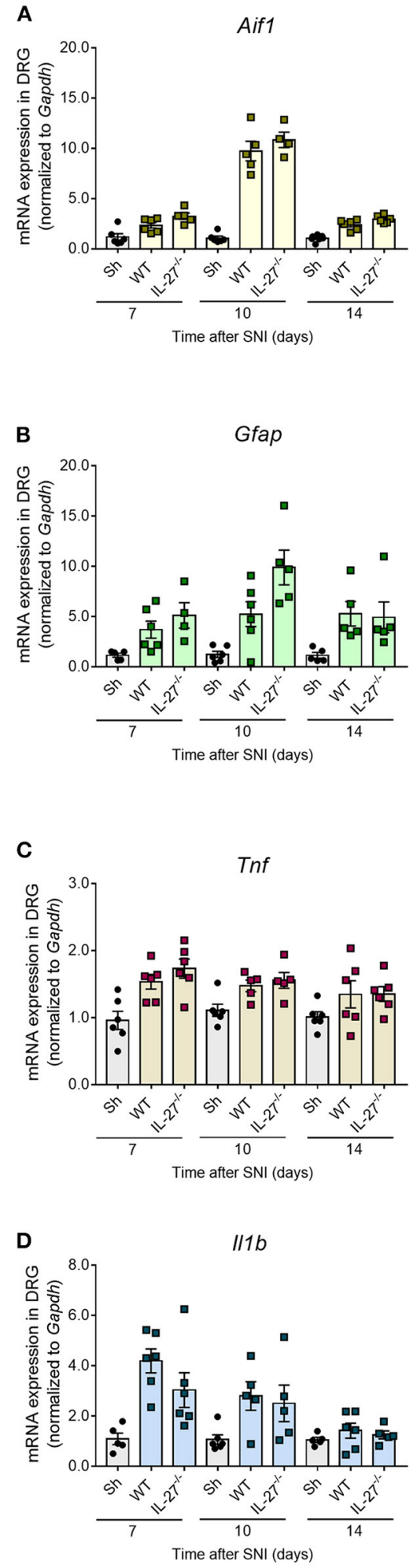

SC

E

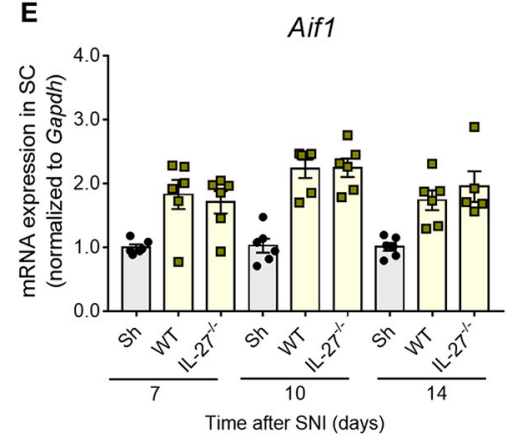

F

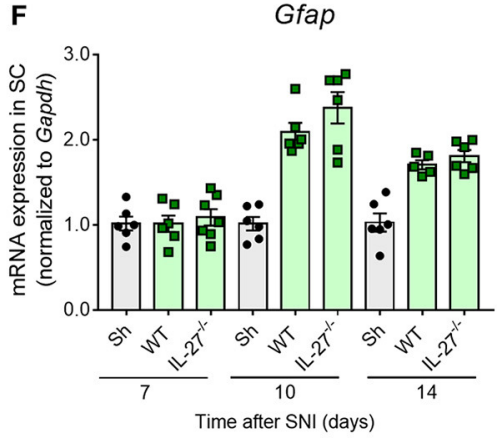

G
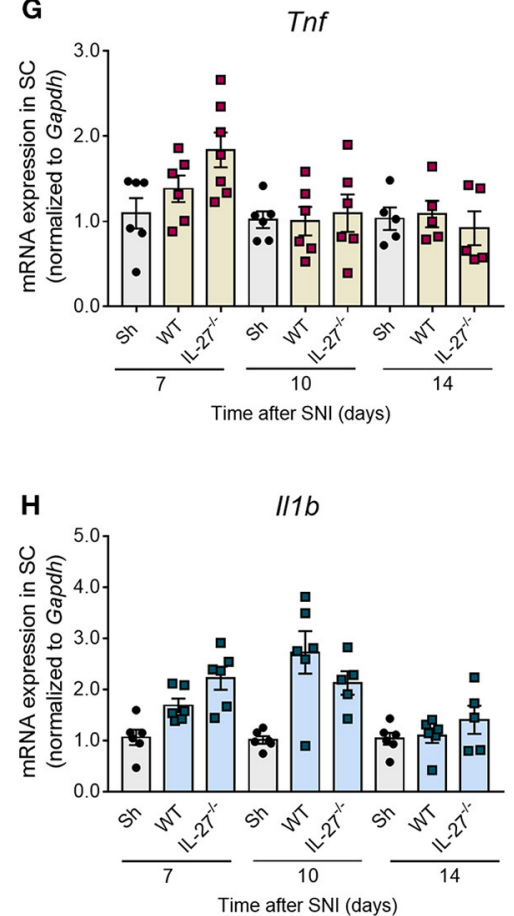

FIGURE 4 | Activation of immune/glial cells and cytokine expression in the DRGs and spinal cord after peripheral nerve injury in the absence of IL-27. Real-time PCR analysis of the expression of glial markers and pro-inflammatory cytokines relative to Gapdh at days 7 , 10, and 14 after SNI or Sham surgery in WT and IL-27-/mice: (A) Aif1, (B) Gfap, (C) Tnf, and (D) //1b expressions in DRGs, (E) Aif1, (F) Gfap, (G) Tnf, and (H) //1b expressions in spinal cord ( $n=7)$. Data are presented as means \pm S.E.M. Data were analyzed by one-way ANOVA followed by Bonferroni post-test. 

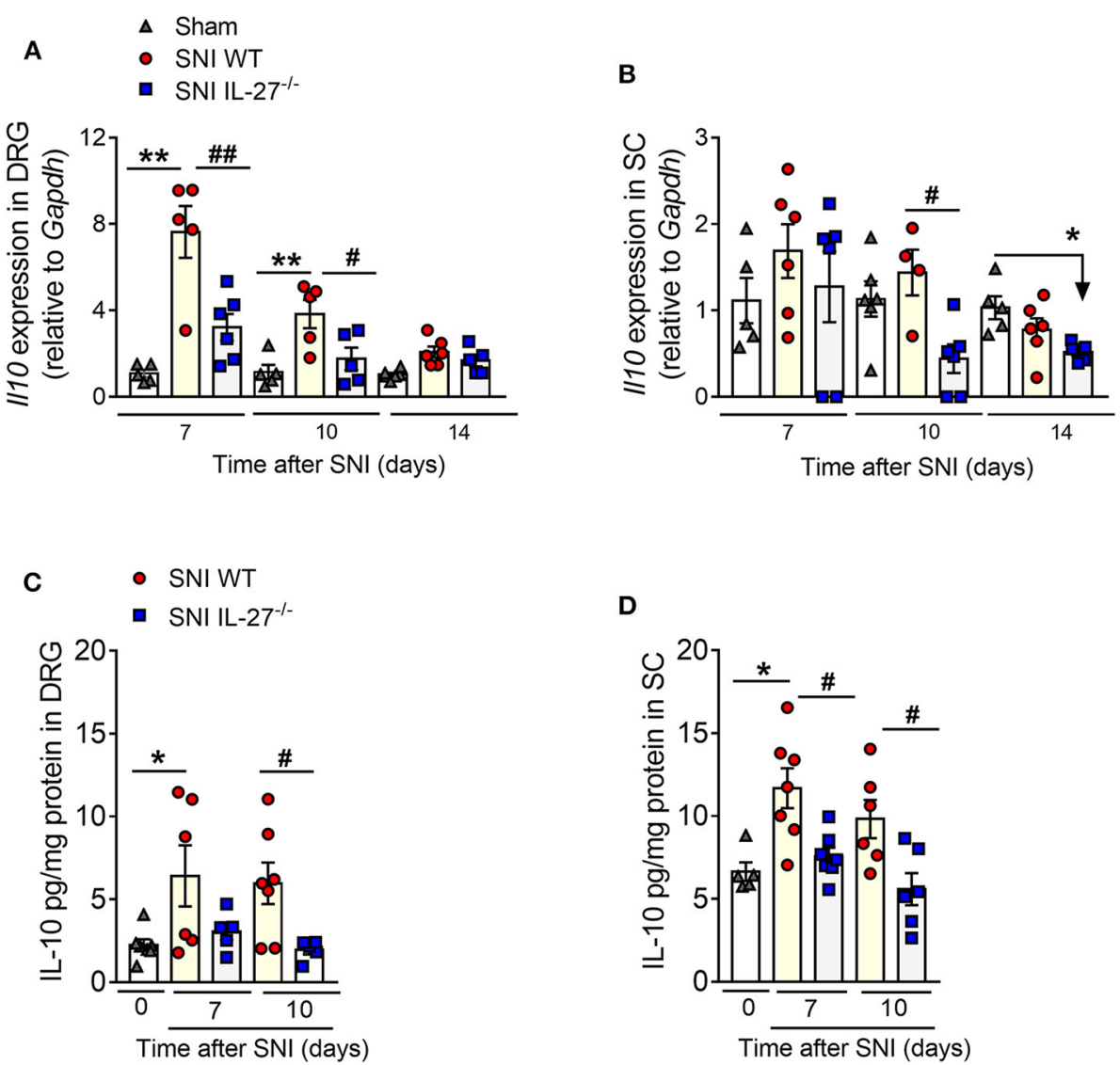

FIGURE 5 | The impact of IL-27 deficiency in anti-inflammatory cytokine expression after peripheral nerve injury. WT and IL-27-/- mice were submitted to SNI or Sham surgeries, and at days 7, 10, and 14, tissues were collected to real-time PCR analysis: (A,B) //10 expression relative to Gapdh in DRGs and in the spinal cord, respectively. (C,D) Level of IL-10 measured by ELISA in DRGs and in the spinal cord, respectively, on days 10 and 14 after SNI or Sham-operated (day 0) in WT and IL-27 ${ }^{-1-}$ mice. Data are presented as means \pm S.E.M $(n=5-7) .{ }^{*} P<0.05$ and ${ }^{\star \star} P<0.01$ vs. Sham-WT. $\# P<0.05$ and $\# \# P<0.01$ vs. SNI-WT (A,B). ${ }^{\star} P<0.05$ and ${ }^{\star \star} P<0.01$ vs. Sham-operated (day 0). ${ }^{\#} P<0.05$ and $\# \# P<0.01$ vs. SNI-WT (C,D). Data were analyzed by one-way ANOVA followed by Bonferroni post-test.
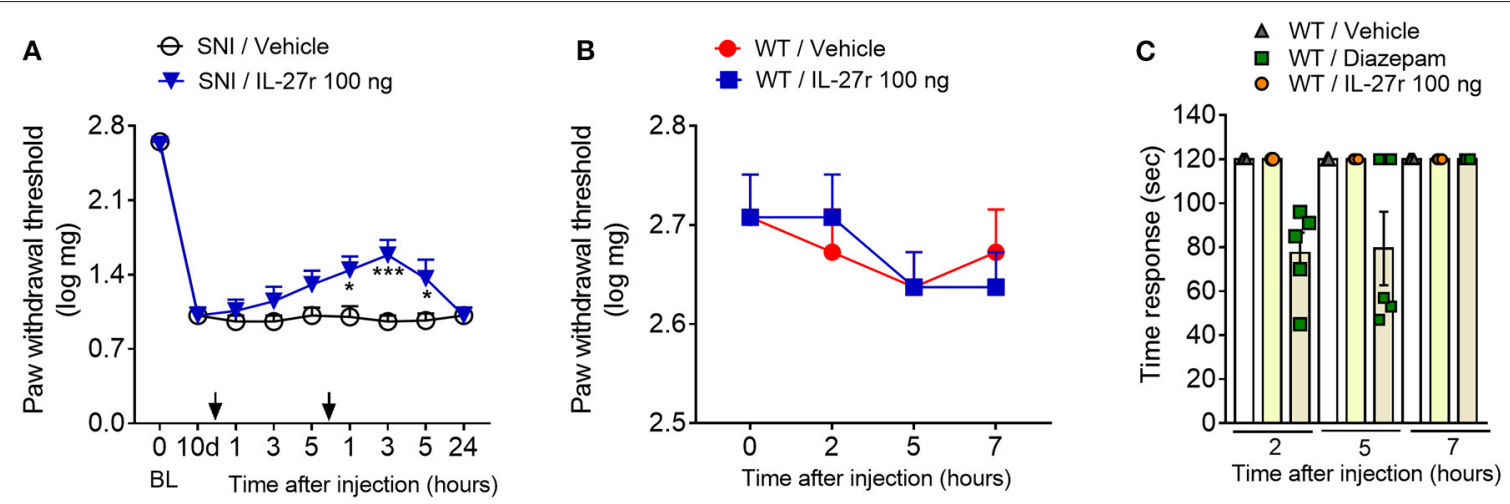

FIGURE 6 | Recombinant IL-27 intrathecally injected partially reverses mechanical hypersensitivity after peripheral nerve injury. (A) WT animals were submitted to SNI surgery and at day 10 were treated i.t. with recombinant IL-27 (IL-27r) or vehicle, and the treatments were repeated after $\sim 5 \mathrm{~h}$; mechanical threshold was evaluated using von Frey filaments $(n=8)$. (B) Effect of recombinant IL-27 in the basal mechanical threshold in WT-naive animals $(n=6)$. (C) Rota-rod test was realized to discard possible non-specific muscle relaxant or sedative effects of recombinant IL-27 in WT-naive animals $(n=5)$. Data are presented as means \pm S.E.M. (A) ${ }^{\star} P<$ $0.05,{ }^{\star \star \star} P<0.001$ vs. SNI-vehicle. (C) ${ }^{\star} P<0.05$ vs. WT-vehicle. Data were analyzed by two-way ANOVA followed by Bonferroni post-test. 

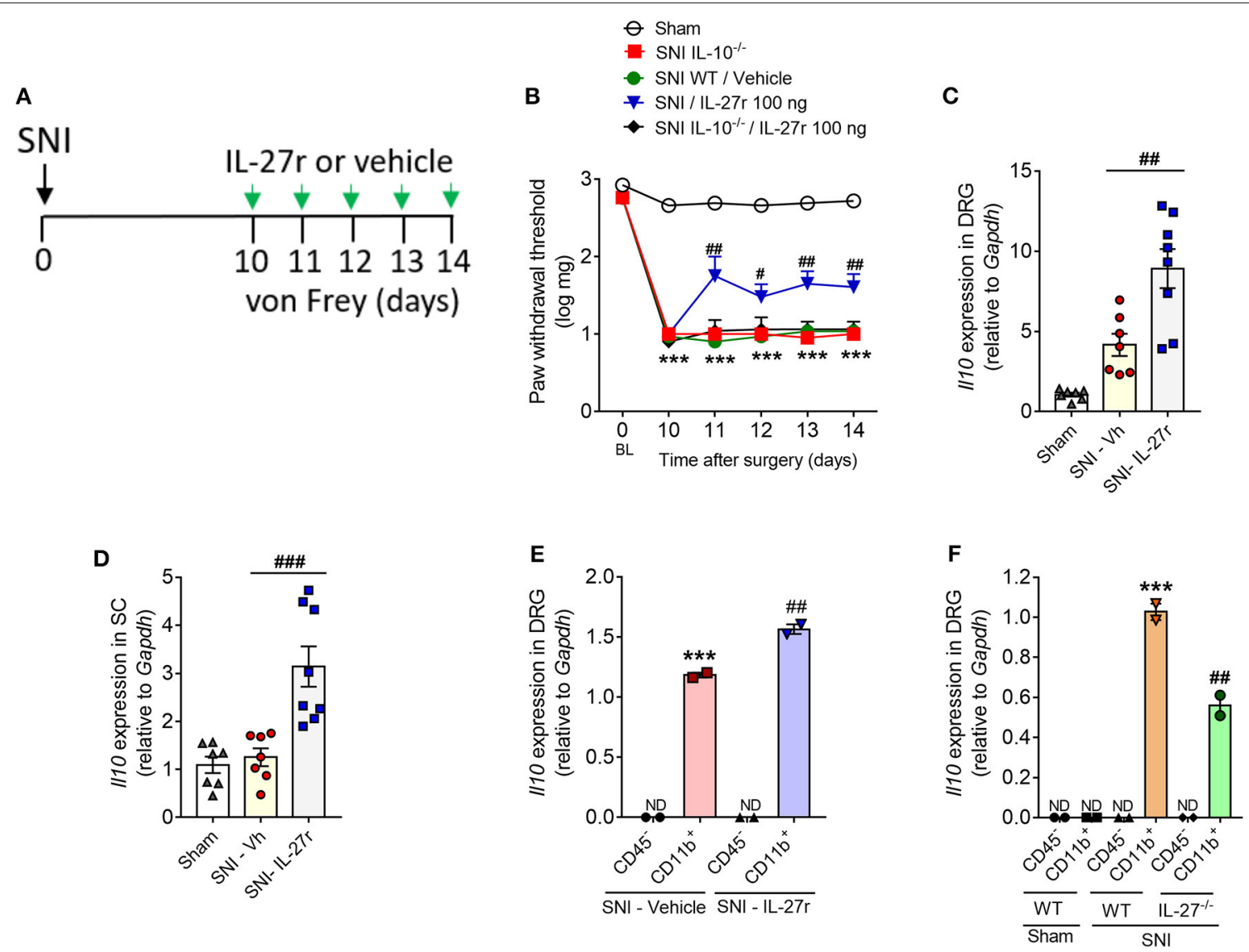

FIGURE 7 | Exogenous IL-27 reduced neuropathic pain through the induction of IL-10. (A) WT and IL-10-/- mice were submitted to SNI (day 0), and on day 10 up to day 14, different groups of animals were treated with recombinant IL-27 or vehicle (i.t) daily. (B) Paw withdrawal thresholds were evaluated using von Frey filament before (day 0 ) and up to 14 days after SNI $(n=8)$. ${ }^{\star \star \star} p<0.001$ vs. Sham-operated mice; ${ }^{*} p<0.05$ and $\# \# p<0.01$ vs. WT-SNI. Real-time PCR analysis of II10 expression relative to Gapdh in WT mice submitted to SNI or Sham surgeries and treated with recombinant IL-27 (SNI-IL27r) or vehicle (SNI-Vh) on day 10 until day 14 (C) in DRGs and (D) in the spinal cord $(n=7-8) .{ }^{* * *} P<0.001$ vs. Sham-operated; \#\#P<0.05 and \#\#\#P<0.001 vs. SNI-Vh. (E) Using the same protocol of treatment, CD45- and CD11 $\mathrm{b}^{+}$cells were isolated from DRGs, by FACS sorting, and levels of $/ 110$ relative to Gapdh expression were quantified using real-time PCR ( $n=2$, pool from eight animals for each). ${ }^{\star \star \star} P<0.001$ vs. CD45- SNI-vehicle. $\# \# P<0.05$ vs. CD11 $\mathrm{b}^{+}$from SNI-vehicle; ND not detected. (F) At 10 days after SNI or Sham surgeries, cells were isolated from DRGs of WT and IL-27-/- and real-time PCR analysis of II10 expression relative to Gapdh was realized $(n=2$, pool from eight animals for each). ${ }^{* \star} P<0.05$ vs. CD45- from SNI-WT; $\# \# P<0.05$ vs. CD11b ${ }^{+}$from Sham-WT; ND, not detected. Data are presented as means \pm S.E.M. Data were analyzed by two-way ANOVA followed by Bonferroni post-test (B) or by one-way ANOVA followed by Tukey post-test (C-F).

cell (microglia and astrocytes) activation in the DRGs and spinal cord, respectively. However, no significant changes in the expression of macrophage/glial cell activation markers and their derived pro-nociceptive cytokines (TNF and IL-1 $\beta$ ) were detected after peripheral nerve injury in the DRGs and spinal cord from IL-27 null mice compared to WT mice. Thus, although IL-27 receptor seems to be confined in macrophage/microglia and astrocyte after peripheral nerve injury, IL-27 effect on neuropathic pain process appears to be independent on the regulation of these cells' activation/proliferation. These data corroborate with the previous study showing no role for IL27 signaling in spinal cord microgliosis after peripheral nerve injury (19).

Concomitantly to the production of pro-inflammatory molecules by immune and glial cells at the sensory ganglia and spinal cord after peripheral nerve injury, there is also evidence suggesting the production of anti-inflammatory/antinociceptive molecules $(12,13,50)$. Among these molecules, IL10 seems to be one of the most important $(15,61,62)$. The antinociceptive role of IL-10 has been extensively explored in different models of pathological pain (63-66). We found that the regulatory role of IL-27 in the development of neuropathic pain is dependent on IL-10 production in the DRGs and spinal cord. At least in the DRGs, IL-27 triggers the induction of IL-10 in macrophages. It is important to point out that IL-10 upregulation after peripheral nerve injury was not exclusively dependent on IL-27 since IL-10 production was not abrogated in IL-27 null mice. Thus, other direct or indirect mechanisms might be involved in the induction of IL-10, such as A2A and $\mathrm{A} 3$ adenosine receptor activation $(67,68)$. In addition, our data corroborate with a recent finding showing that the antinociceptive effect of IL-10 is not dependent on inhibition 
of neuroinflammation (69). Therefore, it is plausible to suggest that IL-10 might reduce neuropathic pain by acting directly on sensitive neurons. In fact, IL-10R1 is expressed in neurons, and its activation directly regulates the functions of the primary sensory neurons $(70,71)$.

The use of exogenous IL-27 has been recognized as a novel biological tool to treat a vast range of inflammatory and autoimmune disease $(28,30,31,72,73)$. In addition to the endogenous involvement of IL-27 in counteracting peripheral nerve injury-induced neuropathic pain development, exogenously administered recombinant IL-27 was also able to reduce neuropathic pain. It is noteworthy that the effective dose of recombinant IL-27 did not alter the mechanical pain threshold, in contrast to previous findings (19). These might be explained by the different dose or route (intrathecal vs. systemic) of IL-27 administration. In addition, the dose of recombinant IL-27 used did not cause any sedative/motor impairment. Then, these data might indicate that IL-27 could be a useful tool to prevent/reduce neuropathic pain in clinical settings.

In summary, our study unraveled the role of IL-27 as a regulatory cytokine that counteracts the development of neuropathic pain through the induction of anti-nociceptive cytokine IL-10. In conclusion, these data provide new insights into the neuroimmune-glia interaction mechanisms involved in the development of neuropathic pain. Finally, they indicate that immunotherapies based on IL-27 could emerge as possible therapeutic approaches for the prevention of neuropathic pain development after peripheral nerve injury.

\section{DATA AVAILABILITY STATEMENT}

The datasets generated for this study are available on request to the corresponding author.

\section{ETHICS STATEMENT}

Animal care and handling procedures were in accordance with the International Association for the Study of Pain guidelines (74)

\section{REFERENCES}

1. van Hecke O, Austin SK, Khan RA, Smith BH, Torrance N. Neuropathic pain in the general population: a systematic review of epidemiological studies. Pain. (2014) 155:654-62. doi: 10.1016/j.pain.2013.11.013

2. Marchand F, Perretti M, McMahon SB. Role of the immune system in chronic pain. Nat Rev Neurosci. (2005) 6:521-32. doi: 10.1038/nrn1700

3. Grace PM, Hutchinson MR, Maier SF, Watkins LR. Pathological pain and the neuroimmune interface. Nat Rev Immunol. (2014) 14:217-31. doi: $10.1038 /$ nri3621

4. Ji RR, Chamessian A, Zhang YQ. Pain regulation by non-neuronal cells and inflammation. Science. (2016) 354:572-7. doi: 10.1126/science. aaf8924

5. Basbaum AI, Bautista DM, Scherrer G, Julius D. Cellular and molecular mechanisms of pain. Cell. (2009) 139:267-84. doi: 10.1016/j.cell.2009. 09.028 for those animals used in pain research, and they were approved by the Committee for Ethics in Animal Research of Ribeirão Preto Medical School -USP (Process no 211/2014).

\section{AUTHOR CONTRIBUTIONS}

MF designed and performed most of the experiments, analyzed the data, and wrote the manuscript. MD-F and FS-C designed and assisted in performing the experiments. RG, RK, FO, and DF assisted in performing some experiments. FC and JA-F reviewed the manuscript and provided expert discussion of the project. TC conceived the study, supervised the overall project, and wrote the manuscript. All authors contributed to manuscript revision and read and approved the submitted version.

\section{FUNDING}

The research leading to these results has received funding from São Paulo Research Foundation (FAPESP) under grant agreements no 2011/19670-0 (Thematic project) and 2013/08216-2 (Center for Research in Inflammatory Disease).

\section{ACKNOWLEDGMENTS}

The authors gratefully acknowledge the technical assistance of Sergio R. Rosa, Ieda Santos, and Katia Santos.

\section{SUPPLEMENTARY MATERIAL}

The Supplementary Material for this article can be found online at: https://www.frontiersin.org/articles/10.3389/fimmu. 2019.03059/full\#supplementary-material

Figure S1 | Representative gating strategies for flow cytometry analysis. After the specified days, DRGs were collected from mice, and CD45- (non-immune cells) and macrophages $\left(\mathrm{CD} 11 \mathrm{~b}^{+} \mathrm{Ly}_{6 \mathrm{G}^{-}}\right)$were isolated using FACS sorting. FSC-H/FSC-A preliminary gate was performed for all cytometry analysis to exclude cell debris and cell doublets. Next, CD45 ${ }^{+}$cells were gated on two populations, CD11 $b^{+} \mathrm{Ly}_{6 G^{+}}$and CD11b+Ly6G ${ }^{-}$. Then, CD45 ${ }^{-}$and $\mathrm{CD} 45^{+} \mathrm{C} 11 b^{+} \mathrm{Ly}_{6 \mathrm{G}^{-}}$were sorted. For all of the experiments, the sample purity was $\sim 70 \%$ for CD11 b ${ }^{+}$Ly6G $^{-}$cells and $\sim 90 \%$ for CD45 ${ }^{-}$cells. We use $\sim 25,000$ cells to isolate mRNA in each group of experiment. 
11. Inoue $\mathrm{K}$. The function of microglia through purinergic receptors: neuropathic pain and cytokine release. Pharmacol Ther. (2006) 109:210-26. doi: 10.1016/j.pharmthera.2005.07.001

12. Xu ZZ, Zhang L, Liu T, Park JY, Berta T, Yang R, et al. Resolvins RvE1 and RvD1 attenuate inflammatory pain via central and peripheral actions. Nat Med. (2010) 16:592-7. doi: 10.1038/nm.2123

13. Üçeyler N, Topuzoglu T, Schiesser P, Hahnenkamp S, Sommer C. IL-4 deficiency is associated with mechanical hypersensitivity in mice. PLoS ONE. (2011) 6:e28205. doi: 10.1371/journal.pone.0028205

14. Chen G, Park CK, Xie RG, Ji RR. Intrathecal bone marrow stromal cells inhibit neuropathic pain via TGF- $\beta$ secretion. J Clin Invest. (2015) 125:3226-40. doi: 10.1172/JCI80883

15. Khan J, Ramadan K, Korczeniewska O, Anwer MM, Benoliel R, Eliav E. Interleukin-10 levels in rat models of nerve damage and neuropathic pain. Neurosci Lett. (2015) 592:99-106. doi: 10.1016/j.neulet.2015.03.001

16. Bobinski F, Teixeira JM, Sluka KA, Santos ARS. Interleukin-4 mediates the analgesia produced by low-intensity exercise in mice with neuropathic pain. Pain. (2018) 159:437-50. doi: 10.1097/j.pain.0000000000001109

17. Pflanz S, Timans JC, Cheung J, Rosales R, Kanzler H, Gilbert J, et al. IL-27, a heterodimeric cytokine composed of EBI3 and p28 protein, induces proliferation of naive CD4+ T cells. Immunity. (2002) 16:779-90. doi: 10.1016/S1074-7613(02)00324-2

18. Pflanz S, Hibbert L, Mattson J, Rosales R, Vaisberg E, Bazan JF, et al. WSX1 and glycoprotein 130 constitute a signal-transducing receptor for IL-27. J Immunol. (2004) 172:2225-31. doi: 10.4049/jimmunol.172.4.2225

19. Sasaguri T, Taguchi T, Murata Y, Kobayashi K, Iizasa S, Iizasa E, et al. Interleukin-27 controls basal pain threshold in physiological and pathological conditions. Sci Rep. (2018) 8:11022. doi: 10.1038/s41598-018-29398-3

20. Lee YS, Amadi-Obi A, Yu CR, Egwuagu CE. Retinal cells suppress intraocular inflammation (uveitis) through production of interleukin-27 and interleukin10. Immunology. (2011) 132:492-502. doi: 10.1111/j.1365-2567.2010. 03379.x

21. Sénécal V, Deblois G, Beauseigle D, Schneider R, Brandenburg J, Newcombe J, et al. Production of IL-27 in multiple sclerosis lesions by astrocytes and myeloid cells: modulation of local immune responses. Glia. (2016) 64:553-69. doi: 10.1002/glia.22948

22. Yoshida H, Hunter CA. The immunobiology of interleukin-27. Annu Rev Immunol. (2015) 33:417-43. doi: 10.1146/annurev-immunol-032414112134

23. Fitzgerald DC, Zhang GX, El-Behi M, Fonseca-Kelly Z, Li H, Yu S, et al. Suppression of autoimmune inflammation of the central nervous system by interleukin 10 secreted by interleukin 27-stimulated T cells. Nat Immunol. (2007) 8:1372-9. doi: 10.1038/ni1540

24. Villarino AV, Larkin J III, Saris CJ, Caton AJ, Lucas S, Wong T, et al. Positive and negative regulation of the IL-27 receptor during lymphoid cell activation. J Immunol. (2005) 174:7684-91. doi: 10.4049/jimmunol.174.12.7684

25. Stumhofer JS, Hunter CA. Advances in understanding the antiinflammatory properties of IL-27. Immunol Lett. (2008) 117:23-30. doi: 10.1016/j.imlet.2008.01.011

26. Yoshida H, Nakaya M, Miyazaki Y. Interleukin 27: a double-edged sword for offense and defense. J Leukoc Biol. (2009) 86:1295-303. doi: 10.1189/jlb.0609445

27. Hölscher C, Hölscher A, Rückerl D, Yoshimoto T, Yoshida H, Mak T, et al. The IL-27 receptor chain WSX-1 differentially regulates antibacterial immunity and survival during experimental tuberculosis. J Immunol. (2005) 174:353444. doi: 10.4049/jimmunol.174.6.3534

28. Batten M, Li J, Yi S, Kljavin NM, Danilenko DM, Lucas S, et al. Interleukin 27 limits autoimmune encephalomyelitis by suppressing the development of interleukin 17-producing T cells. Nat Immunol. (2006) 7:92936. doi: 10.1038/ni1375

29. de Aquino MT, Kapil P, Hinton DR, Phares TW, Puntambekar SS, Savarin C, et al. IL-27 limits central nervous system viral clearance by promoting IL-10 and enhances demyelination. J Immunol. (2014) 193:285-94. doi: 10.4049/jimmunol.1400058

30. Fitzgerald DC, Ciric B, Touil T, Harle H, Grammatikopolou J, Das Sarma J, et al. Suppressive effect of IL-27 on encephalitogenic Th17 cells and the effector phase of experimental autoimmune encephalomyelitis. J Immunol. (2007) 179:3268-75. doi: 10.4049/jimmunol.179.5.3268
31. Niedbala W, Cai B, Wei X, Patakas A, Leung BP, McInnes IB, et al. Interleukin 27 attenuates collagen-induced arthritis. Ann Rheum Dis. (2008) 37:1474-9. doi: 10.1136/ard.2007.083360

32. Pickens S R, Chamberlain ND, Volin MV, Mandelin AM II, Agrawal H, Matsui $\mathrm{M}$, et al. Local expression of interleukin-27 ameliorates collagen-induced arthritis. Arthritis Rheum. (2011) 63:2289-98.doi: 10.1002/art.30324

33. Tanida S, Yoshitomi H, Ishikawa M, Kasahara T, Murata K, Shibuya H, et al. IL-27-producing CD14(+) cells infiltrate inflamed joints of rheumatoid arthritis and regulate inflammation and chemotactic migration. Cytokine. (2011) 55:237-44. doi: 10.1016/j.cyto.2011.04.020

34. Nieuwenhuis EE, Neurath MF, Corazza N, Iijima H, Trgovcich J, Wirtz S, et al. Disruption of $\mathrm{T}$ helper 2-immune responses in epstein-barr virusinduced Gene 3-deficient mice. Proc Natl Acad Sci USA. (2002) 99:16951-6. doi: 10.1073/pnas.252648899

35. Kühn R, Löhler J, Rennick D, Rajewsky K, Müller W. Interleukin10-deficient mice develop chronic enterocolitis. Cell. (1993) 75:263-74. doi: 10.1016/0092-8674(93)80068-P

36. Jung S, Aliberti J, Graemmel P, Sunshine MJ, Kreutzberg GW, Sher A, et al. Analysis of fractalkine receptor CX(3)CR1 function by targeted deletion and green fluorescent protein reporter gene insertion. Mol Cell Bio. (2000) 20:4106-14. doi: 10.1128/MCB.20.11.4106-4114.2000

37. Decosterd I, Woolf CJ. Spared nerve injury: an animal model of persistent peripheral neuropathic pain. Pain. (2000) 87:149-58. doi: 10.1016/S0304-3959(00)00276-1

38. Hunskaar S, Hole K. The formalin test in mice: dissociation between inflammatory and non-inflammatory pain. Pain. (1987) 30:103-14 doi: 10.1016/0304-3959(87)90088-1

39. Kuraishi Y, Harada Y, Aratani S, Satoh M, Takagi H. Separate involvement of the spinal noradrenergic and serotonergic systems in morphine analgesia: the differences in mechanical and thermal algesic tests. Brain Res. (1983) 273:245-52. doi: 10.1016/0006-8993(83)90849-1

40. Choi Y, Yoon YW, Na HS, Kim SH, Chung JM. Behavioral signs of ongoing pain and cold allodynia in a rat model of neuropathic pain. Pain. (1994) 59:369-76. doi: 10.1016/0304-3959(94)90023-X

41. Cunha TM, Verri WA Jr, Vivancos GG, Moreira IF, Reis S, Parada CA, et al. An electronic pressure-meter nociception paw test for mice. Braz J Med Biol Res. (2004) 37:401-7. doi: 10.1590/S0100-879X2004000300018

42. Ribeiro RA, Vale ML, Thomazzi SM, Paschoalato AB, Poole S, Ferreira SH, et al. Involvement of resident macrophages and mast cells in the writhing nociceptive response induced by zymosan and acetic acid in mice. Eur J Pharmacol. (2000) 387:111-8. doi: 10.1016/S0014-2999(99)00790-6

43. Papir-Kricheli D, Frey J, Laufer R, Gilon C, Chorev M, Selinger $Z$, et al. Behavioural effects of receptor-specific substance P agonists. Pain. (1987) 31:263-76. doi: 10.1016/0304-3959(87)9 0041-8

44. Livak KJ, Schmittgen TD. Analysis of relative gene expression data using realtime quantitative PCR and the 2[-delta delta C(T)] method. Methods. (2001) 25:402-8. doi: 10.1006/meth.2001.1262

45. Sorge RE, Mapplebeck JC, Rosen S, Beggs S, Taves S, Alexander JK, et al. Different immune cells mediate mechanical pain hypersensitivity in male and female mice. Nat Neurosci. (2015) 18:1081-3. doi: 10.1038/nn.4053

46. Santa-Cecília FV, Ferreira DW, Guimaraes RM, Cecilio NT, Fonseca $\mathrm{MM}$, Lopes $\mathrm{AH}$, et al. The NOD2 signaling in peripheral macrophages contributes to neuropathic pain development. Pain. (2009) 160:102-16. doi: 10.1097/j.pain.0000000000001383

47. Austin PJ, Moalem-Taylor G. The neuro-immune balance in neuropathic pain: involvement of inflammatory immune cells, immunelike glial cells and cytokines. J Neuroimmunol. (2010) 229:26-50. doi: 10.1016/j.jneuroim.2010.08.013

48. Lee HL, Lee KM, Son SJ, Hwang SH, Cho HJ. Temporal expression of cytokines and their receptors mRNAs in a neuropathic pain model. Neuroreport. (2004) 15:2807-11.

49. Milligan ED, Langer SJ, Sloane EM, He L, Wieseler-Frank J, O'Connor K, et al. Controlling pathological pain by adenovirally driven spinal production of the anti-inflammatory cytokine, interleukin-10. Eur J Neurosci. (2005) 21:2136-48. doi: 10.1111/j.1460-9568.2005.04057.x

50. Jancálek R, Dubový P, Svízenská I, Klusáková I. Bilateral changes of TNF-alpha and IL-10 protein in the lumbar and cervical dorsal root ganglia following 
a unilateral chronic constriction injury of the sciatic nerve. J Neuroinflam. (2010) 7:11. doi: 10.1186/1742-2094-7-11

51. Milligan ED, Penzkover KR, Soderquist RG, Mahoney MJ. Spinal interleukin10 therapy to treat peripheral neuropathic pain. Neuromodulation. (2012) 15:520-6. doi: 10.1111/j.1525-1403.2012.00462.x

52. Hung AL, Lim M, Doshi TL. Targeting cytokines for treatment of neuropathic pain. Scand J Pain. (2017) 17:287-93. doi: 10.1016/j.sppain.2017.08.002

53. Thacker MA, Clark AK, Marchand F, McMahon SB. Pathophysiology of peripheral neuropathic pain: immune cells and molecules. Anesth Analg. (2007) 105:838-47. doi: 10.1213/01.ane.0000275190.42912.37

54. Clark AK, Old EA, Malcangio M. Neuropathic pain and cytokines: current perspectives. J Pain Res. (2013) 6:803-14. doi: 10.2147/JPR.S53660

55. Berta T, Qadri Y, Tan PH, Ji RR. Targeting dorsal root ganglia and primary sensory neurons for the treatment of chronic pain. Expert Opin Ther Targets. (2017) 21:695-703. doi: 10.1080/14728222.2017.1328057

56. Denk F, Crow M, Didangelos A, Lopes DM, McMahon SB. Persistent alterations in microglial enhancers in a model of chronic pain. Cell Rep. (2016) 15:1771-81. doi: 10.1016/j.celrep.2016.04.063

57. Whitehead KJ, Smith CG, Delaney SA, Curnow SJ, Salmon M, Hughes JP, et al. Dynamic regulation of spinal pro-inflammatory cytokine release in the rat in vivo following peripheral nerve injury. Brain Behav Immun. (2010) 24:569-76. doi: 10.1016/j.bbi.2009.12.007

58. Scholz J, Woolf CJ. The neuropathic pain triad: neurons, immune cells and glia. Nat Neurosci. (2007) 10:1361-8. doi: 10.1038/nn1992

59. Scheller J, Schuster B, Hölscher C, Yoshimoto T, Rose-John S. No inhibition of IL-27 signaling by soluble gp130. Biochem Biophys Res Commun. (2005) 326:724-8. doi: 10.1016/j.bbrc.2004.11.098

60. Wang S, Miyazaki Y, Shinozaki Y, Yoshida H. Augmentation of antigenpresenting and Th1-promoting functions of dendritic cells by WSX-1(IL-27R) deficiency. J Immunol. (2007) 179:6421-8. doi: 10.4049/jimmunol.179.10.6421

61. Alexander GM, van Rijn M, van Hilten JJ, Perreault MJ, Schwartzman RJ. Changes in cerebrospinal fluid levels of pro-inflammatory cytokines in CRPS. Pain. (2005) 116:213-9. doi: 10.1016/j.pain.2005. 04.013

62. Backonja MM, Coe CL, Muller DA, Schell K. Altered cytokine levels in the blood and cerebrospinal fluid of chronic pain patients. J Neuroimmunol. (2008) 195:157-63. doi: 10.1016/j.jneuroim.2008.01.005

63. Ledeboer A, Jekich BM, Sloane EM, Mahoney JH, Langer SJ, Milligan $\mathrm{ED}$, et al. Intrathecal interleukin-10 gene therapy attenuates paclitaxelinduced mechanical allodynia and proinflammatory cytokine expression in dorsal root ganglia in rats. Brain Behav Immun. (2007) 21:686-98. doi: 10.1016/j.bbi.2006.10.012

64. Wagner R, Janjigian M, Myers RR. Anti-inflammatory interleukin-10 therapy in CCI neuropathy decreases thermal hyperalgesia, macrophage recruitment, and endoneurial TNF-alpha expression. Pain. (1998) 74:35-42. doi: 10.1016/S0304-3959(97)00148-6

65. Alaaeddine N, Di Battista JA, Pelletier JP, Kiansa K, Cloutier JM, MartelPelletier J. Inhibition of tumor necrosis factor alpha-induced prostaglandin E2 production by the antiinflammatory cytokines interleukin-4, interleukin-10, and interleukin-13 in osteoarthritic synovial fibroblasts: distinct targeting in the signaling pathways. Arthritis Rheum. (1999) 42:710-718. doi: 10.1002/ 1529-0131(199904)42:4<710::AID-ANR14>3.0.CO;2-4

66. Helmark IC, Mikkelsen UR, Børglum J, Rothe A, Petersen MC, Andersen O, et al. Exercise increases interleukin-10 levels both intraarticularly and perisynovially in patients with knee osteoarthritis: a randomized controlled trial. Arthritis Res Ther. (2010) 12:R126. doi: 10.1186/ar3064

67. Janes K, Esposito E, Doyle T, Cuzzocrea S, Tosh DK, Jacobson KA, et al. A3 adenosine receptor agonist prevents the development of paclitaxel-induced neuropathic pain by modulating spinal glial-restricted redox-dependent signaling pathways. Pain. (2014) 155:2560-7. doi: 10.1016/j.pain.2014.09.016

68. Kwilasz AJ, Ellis A, Wieseler J, Loram L, Favret J, McFadden A, et al. Sustained reversal of central neuropathic pain induced by a single intrathecal injection of adenosine A2A receptor agonists. Brain Behav Immun. (2018) 69:470-9. doi: 10.1016/j.bbi.2018.01.005

69. Wu HY, Mao XF, Tang XQ, Ali U, Apryani E, Liu H, et al. Spinal interleukin10 produces antinociception in neuropathy through microglial $\beta$-endorphin expression, separated from antineuroinflammation. Brain Behav Immun. (2018) 73:504-19. doi: 10.1016/j.bbi.2018.06.015

70. Shen KF, Zhu HQ, Wei XH, Wang J, Li YY, Pang RP, et al. Interleukin-10 down-regulates voltage gated sodium channels in rat dorsal root ganglion neurons. Exp Neurol. (2013) 247:466-75. doi: 10.1016/j.expneurol.2013.01.018

71. Moore KW, de Waal Malefyt R, Coffman RL, O'Garra A. Interleukin-10 and the interleukin-10 receptor. Annu Rev Immunol. (2001) 19:683-765. doi: 10.1146/annurev.immunol.19.1.683

72. Rostami A, Ciric B. Role of Th17 cells in the pathogenesis of CNS inflammatory demyelination. $J$ Neurol Sci. (2013) 333:76-87. doi: 10.1016/j.jns.2013.03.002

73. Sasaoka T, Ito M, Yamashita J, Nakajima $K$, Tanaka I, Narita $M$, et al. Treatment with IL-27 attenuates experimental colitis through the suppression of the development of IL-17-producing T helper cells. Am J Physiol Gastrointest Liver Physiol. (2011) 300:G568-76. doi: 10.1152/ajpgi.00329.2010

74. Zimmermann M. Ethical guidelines for investigations of experimental pain in conscious animals. Pain. (1983) 16:109-10. doi: 10.1016/0304-3959(83)90201-4

Conflict of Interest: The authors declare that the research was conducted in the absence of any commercial or financial relationships that could be construed as a potential conflict of interest.

Copyright $\odot 2020$ Fonseca, Davoli-Ferreira, Santa-Cecília, Guimarães, Oliveira, Kusuda, Ferreira, Alves-Filho, Cunha and Cunha. This is an open-access article distributed under the terms of the Creative Commons Attribution License (CC BY). The use, distribution or reproduction in other forums is permitted, provided the original author(s) and the copyright owner(s) are credited and that the original publication in this journal is cited, in accordance with accepted academic practice. No use, distribution or reproduction is permitted which does not comply with these terms. 